\title{
Long time behavior of a wave equation with time-varying delay and acoustic boundary conditions
}

\author{
Jong-Yeoul Park ${ }^{1}$ and Jae Jeong ${ }^{2}$ \\ ${ }^{1}$ Pusan National University \\ ${ }^{2}$ Dong Eui University
}

September 23, 2020

\begin{abstract}
In this paper, we consider the following wave equation with time-varying delay and acoustic boundary conditions in a bounded domain. By virtue of Galerkin method, we prove the existence and uniqueness of global solution under some general assumptions for the above equation. And the existence of a compact global attractor is proved.
\end{abstract}

\section{Hosted file}

jum19-1.pdf available at https://authorea.com/users/361108/articles/482636-long-timebehavior-of-a-wave-equation-with-time-varying-delay-and-acoustic-boundary-conditions 